\title{
SPECTROPHOTOMETRY AND MULTICOLOUR IMAGERY OF THE PLANETARY NEBULA AROUND THE P CYGNI STAR AG CARINAE
}

\author{
C. ROSSI and A. ALTAMORE \\ Ist. Astronomico, Univ. La Sapienza, Via Lancisi 29, 00161 Roma, Italy \\ R.D.D. COSTA, A. DAMINELI NETO and J.A. DE FREITAS PACHECO \\ Inst. Astron. e Geofís., Caixa Postal 9638, 01065 São Paulo SP, Brasil \\ and
}

A. CASSATElla, A.R. MARENZI, P. PERSI, V.F. POlCARO and R. VIOTTI Ist. Astrofisica Spaziale, CNR, Via Fermi 21, 00044 Frascati RM, Italy

Some of the high luminosity stars in our Galaxy are surrounded by planetarylike nebulae formed by material ejected from the central star. The most interesting case is that of the ring nebula PK 289- $0^{\circ} 1$ around the P Cygni star AG Car. Long slit spectroscopy shows that nitrogen is overabundant and oxygen underabundant in the nebula. The $\mathrm{H} \alpha /[\mathrm{NII}]$ ratio is lower in the nebula with respect to the surrounding $\mathrm{H}$ II region, possibly as a result of the $\mathrm{N}$ overabundance in the stellar wind. The emission line peak separation confirms a model of a distorted spherical shell expanding at $66 \mathrm{~km} \mathrm{~s}^{-1}$. The scattered star's spectrum is observable near the star, suggesting the presence of circumstellar dust grains. A nebular mass of at least $2.7 \mathrm{M}_{\odot}$ is derived. While the nebula in the $\mathrm{H} \alpha$ imagery reveals the ring-like shape with many structures, in the blue it is much fainter and smoother. No nebular emission was detected in the JHK bands, suggesting a low dust temperature. 